\title{
Properties of Long Memory in Return innovations from Emerging Agricultural Markets
}

\author{
Deebom Zorle Dum, Ette Harrison Etuk and Nwikorga Legborsi Wisdom \\ Rivers state University, Port Harcourt, Nigeria \\ DOI: https://dx.doi.org/10.51584/IJRIAS.2021.6402
}

\begin{abstract}
The study investigates properties of Long Memory in return innovations from emerging agricultural markets. The aim of the study is to determine the presence of long memory properties in emerging agricultural markets return innovations using; Hurst-Classical Mandelbrot's R/S statistics, Lo's statistics, and semi-parametric GPH statistics. The data used in the analysis include three Agricultural market indices: wheat, sorghum and rice. The data were extracted from: https://www.indexmundi.com/agriculture/ spanning from September, 1990 to 30th August, 2020, making a total of 1080 data points used in the study. From the results of the findings, it was confirmed that the study was in line with the Taylor effect as the values of the estimated difference (d) parameters ofthe absolute returns are greater than those of the squared returns except in the case of $M=T^{0.08}(0.195(0.004))$ which is greater than that of the square returns on price with estimated difference (d) of $M=T^{0.08}(0.189(0.006))$. From all indications there was no presence of long-term memory in the continuous market returns, indicating that the emerging agricultural market returns follow a random walking process. Furthermore, in the continuous return series of the indices, the absence of long memory did not show any evidence against the weak form of market efficiency in the returns on price in the emerging agricultural market. The lack of long memory in this case simply implies that agricultural produce from these markets were not systematically over-valued or under-valued, justifying the inactive investment in the agricultural sector (index). In this case, investors can expect a normal rate of return (risk-adjusted) while agriculturists should expect to receive a fair value for the products they sell.
\end{abstract}

Keywords: Long Memory, Return, Innovations, Emerging, Agricultural Markets

\section{INTRODUCTION}

\subsection{Background to the Study}

$\mathrm{I}^{\mathrm{n}}$ n recent years, extreme fluctuations and high price spikes for agricultural commodities have led to higher volatility, competing for market participation among investors and speculators not to achieve maximum returns on their investments. Sequel to the above, policy makers have also (recently) redirected their attention to agricultural commodity markets to tackle issues such as regulating competing market participation among investors, excessive speculative interest, price instability in the financial market, and a lack of convergence between the futures markets and the cash markets. The development and management of proper hedging programme for volatility analysis are vital for corporations in the management of commodity risk. Investment advisors, traders and managers of hedge funds see the need to properly examine properties of long memory models in return innovations. This analysis is crucial for maintaining their asset portfolios and to enable farmers to also take part in the timing of their marketing decisions. The benefit of studying agricultural commodity returns on price is significant for traders when pricing premiums for options and also to give direction and magnitude to precision, in terms of forecasting.

According to Naveen(1), one of the key innovations in science and statistics is a situation that is observed to exist or occur, particularly one whose cause or explanation is generating conscience among researchers, econometrics and religious believers. A phenomenon that is often referred to as" long memory "or" long-range dependence" is one of such situation. It is used to describe the strong correlation or dependence between data from time series. It has to do with the persistent correlation in a time series between distant observations. It plays a significant role, with implications for forecast ability, differences in specific frequencies, and trends. Mandelbrot and Wallis (2) referred to it as the Joseph effect:a biblical reference as foretold in the Old Testament prophet book of Moses (Genesis 41:1-52), about the seven years of plenty followed by the seven years of scarcity that Egypt was to experience and also the Yusuf story in the Islamic Quran.

Generally speaking, using our common parlance, this suggests that good times lead to good times and bad times lead to bad times. The presence of long memory in the return innovations of emerging agriculture sector markets has imperative implications for market efficiency and stock market returns' random walk behaviour. This is because, as we all know, volatility in the investment industry is characterized by a long memory. The consensus began to take shape with studies involving hyperbolic decay of stock index volatility autocorrelations (3), but gained popularity as fractionally integrated GARCH models found their way into the literature on volatility modeling. There are many studies from developed markets that show that long memory or long-range dependence is exhibited by conditional volatility of returns on asset prices.

In stock returns, Andersen and Bollerslev (4); Andersen and Bollerslev (5), Ding, et al.(3), and Breidtet al(6) find evidence of long-memory stochastic volatility, and Harvey (7) finds evidence in exchange rates long-memory. Liow (8) investigates the persistence of total-hedge and public real estate series in international real estate market return and 
volatility. He finds little evidence of long memory in the return series, but the overall long memory volatility effect appears to be real and was less likely to be triggered for some Asia-Pacific real estate markets by changes in invariance. These findings led to the development of alternative volatility models such as the Fractionally Integrated Generalized Autoregressive Conditional Heteroskedasticity(FIGARCH) model. In another development, an estimation method based on the spectral approximation to the probability of Gaussian distribution was proposed by Harvey (7), and the finite sample properties of long memory were analyzed by Perez and Ruiz (8). Granger and Hyung (10) report that long memory phenomenon of market return through structural changes in GARCH and the time series with structural return breaks can induce a strong persistence in the autocorrelation function of financial series and thus produce spurious long memory.

Banerjee and Urga (11) provide both long memory and structural breaks with a comprehensive literature survey which are almost observationally equivalent in characteristics. The existence of long memory dynamics triggers nonlinear reliance on average returns of assets. As an effective market hypothesis is rejected because stock market prices do not follow a random walk, the primary implication of this situation is that return predictability is possible (12). Brooks (13) notes that it is not good to work directly with the exact price series for several statistical reasons; hence the raw price series is mostly converted into returns. Also, the results from the calculation of the returns have been confirmed to be relevant in financial modeling. This is because using returns in estimation make the series to be unit-free, which is one of the things that lead to biased estimation in financial modeling. For example, supposing a monthly or call it annual return were estimated to be 10 percent, then investors know that there is a need for them to get $\$ 110$ back for a $\$ 100$ investment or $\$ 1100$ for a $\$ 1000$ investment, and so on(13). To accurately estimate returns from a series, Brooks (13) suggests that there are two methods used to estimates return from a series of prices, and these involve the formation of simple and continuously compounded returns.

In the case of simple returns, it is seen as multiplying the asset price at time lag divided by the asset price at a time by a hundred percent, while continuously compounded returns denoted by "rt" can be seen in many other cases as multiplying a hundred percent by the natural logarithms of lag time divided on the spot price. Also, returns on price in most financial studies are considered to give a more precise estimate when it is used in doing estimation than the actual series. One of the reasons why it is said to give a more precise estimate is that from economic perspective returns on an asset are assumed to be a scale-free summary of an investment opportunity (1). Also, from a statistical point of view returns on prices are easily handled in computation than the actual price series because returns on prices exhibit more attractive statistical properties than those of the former. For example, the return series reveals the persistent effect of volatility in the second central raw moment of most financial data series.
In another development, statisticians and econometricians are interested in using returns on an asset series because it is useful in establishing the relationship between the variables you are interested in with other economic quantities. Similarly, the empirical properties of return innovation include high-frequency observation. Return innovation usually show a higher peak around it's mean and flatter tails than that of their corresponding normal distribution; high excessive kurtosis, the mean of logarithmic return series always revolved round zero, evidence of lack of autocorrelation at its level form, but usually represented in the form of a series square of continuous return (long-returns) (14). Franket et al (15) noted that in financial theory the relationship between risk and returns on price series play an important role in future price determination and forecasting. They further explain that many theoretical models, for example, the capital asset price model implies a linear relationship between the expected returns on a market portfolio and the variance. If the risk (i.e. the conditions variance) is not constant over time, the conditional expectation of the market returns will be a linear function of the conditional variance. Eduardo (16) confirmed that asset prices are generally non-stationary, but their returns are usually stationary. Although, even when they are stationary sometimes they exhibit the characteristic of a series that are fractionally integrated.

He further explains that return series usually show no or little autocorrelation. Also, the volatility of the returns on price series appears to be clustered and they often move together. As the return series is not normally distributed it appears that the series exhibits thick - failed distributional properties and changes in stock prices tend to be negatively correlated with changes in volatility. Conversely, when the asset under consideration is a stock or portfolio of stocks, Brooks (13) opines that in such a situation the total returns to holding is the addition of the capital gain and dividends paid during the holding period. However, researchers often neglect dividend payment because they feel it is quite challenging and mostly lead to the underestimation of the total returnsthat accrue to investors. Following this process may likely lead to underestimation for the very short holding period, which has a severe influence on cumulative returns over investment horizons of several years. On the other hand, neglecting dividends in the course of estimating total return also has a distortional effect on the cross-section of returns on prices. For example, neglecting dividends simply means that 'growth' stocks, with large price gain, will be favoured over income stocks (for utilities and other industries) that pay high dividends. Also, Changyonget al (17) noted that using the $\log$ transformation helps in reducing the variability in data and equally make it to conform with the normality and to avoid spurious estimation. As indicated in the next section, the concept of long memory has been widely investigated in other fields but not limited research has been done on agricultural markets. It is against this background that this present study aims at investigating the properties of long 
memory models in emerging agricultural markets with emphasis on return innovations such as continuous, absolute and square return series.

\section{CONCEPT OF LONG MEMORY}

The concept of long memory or long-range dependence has to do with a series having a higher-order correlation structure. If a time series is said to follow a long-memory process, there is a persistent temporal dependence among observations that are widely separated over time. Such series display hyperbolically decaying autocorrelations and distributions of low frequency. The presence of long memory has some serious significance in the dynamics of the time series system. According to Franket et al (18), the presence of long memory causes shock at one point in time that leads to increased risk and uncertainty in the market which does not die down quickly, instead it remains on, although in a decaying fashion, and influences future results.

Also, a long memory process can be considered as a fractionally integrated process, i.e., between the stationary and unit root process. Like a stationary process, with finite memory, it is also a mean-reverting process, i.e., after experiencing a shock; it can quickly bounce to balance, although it shows a much slower hyperbolic rate of decay rather than exponential, unlike the autoregressive stationary process that takes much longer to bounce back to equilibrium. If a time series has a unit root at a level but its first differences are stationary, it is said to be an I(1) (order one integrated process). It is said that a stationary process is an $\mathrm{I}(0)$ process (integrated with order zero). The long memory process is $\mathrm{I}(\mathrm{d})$, where $\mathrm{d}$ is between 0 and 1, i.e. a fraction, using the same notation. Long memory financial time series have typical spectral power concentrations near-zero or at low frequencies in the frequency domain, and then as the frequency increases, it decreases exponentially and smoothly (18). These statistical properties behaviour exhibited by Long Memory has generated a lot of studies. Some of these studies can be found in different areas such as returns on the stock market $(19,20 ; 12 ; 21 ; 22 ; 23,13$ and 24$)$; returns on the exchange rate $(25,5)$; real estate markets $(26,27)$ and futures market returns $(28 ; 29)$, whereas limited studies have been done in the area of agricultural commodities (30, 31, and 32) and this shows that there exists a gap between this study and other related studies. This study is aimed at filling this gap. Also, one of the primary motivations for this study is to better understand recent increases in world food price volatilities, especially wheat, sorghum and rice.

\section{METHODS FOR TESTING LONG MEMORY PROPERTIES IN RETURN INNOVATIONS}

It is a well-known fact that many financial time series are highly persistent, implying that an unforeseeable shock to the variable has long-lasting impacts. In this case, the absolute and squared returns of autocorrelation functions of the time series exhibit slow decay. In examining properties of longmemory models in return innovations from emerging developing agricultural markets, it is well known from several studies that strong autocorrelation of long-memory processes make statistical fluctuations very large. These make the empirical determination of the long-memory property of a time series become difficult. Thus, long-memory tests tend to require large amounts of data. We tested the stationary properties of all the data series using the Augmented DickeyFuller (ADF) test, Phillips-Perron (PP) test, and KPSS in this study. In an attempt to capture the long-memory properties of the emerging agricultural markets data, using classical rescaled-range $(\mathrm{R} / \mathrm{S})$ analysis $(33 ; 34)$, modified rescaledrange $(\mathrm{R} / \mathrm{S})$ analysis introduced by Lo (35), and the spectral regression method suggested by Geweke and Porter-Hudak (36) on the raw data, the continuous, absolute and squared return series. The above tests were used in the study and the methods referred to are detailed below.

\subsubsection{Lo's R/S Statistics}

In the year 1951, Hurst originally proposed the Rescaled Range (R/S) statistics which was later modified by Lo in 1991(1). The later modification was carried out to make sure that the original statistics is not robust to short range dependence. This led to the introduction of the modified Rescaled Range (R/S) statistics and it states thus:

$$
\begin{aligned}
& Q_{T}=\frac{1}{\hat{\sigma}_{T}(q)}\left[\max _{1 \leq k \leq T} \sum_{t=1}^{K}(y-\bar{y})-\min _{1 \leq k \leq T} \sum_{t=1}^{K}(y-\bar{y})\right] \\
& \text { Where } \bar{y}=\frac{\sum_{i=1}^{T} y_{i}}{T} \text { and } \hat{\sigma}(\mathrm{q}) \text { represent the square root of the }
\end{aligned}
$$
Newey-West estimate of the long-run variance with bandwidth q.

\subsubsection{GPH Test}

The GPH which stands forGeweke and Porter-Hudak was proposed in 1983 as semi-parametric approach to test for long memory. The Geweke and Porter-Hudak method used the regression below in its estimation, the regression is stated as thus:

$$
\operatorname{In} \mathrm{I}\left(w_{j}\right)=\beta-d \operatorname{In}\left[4 \sin ^{2}\left(\frac{w_{j}}{2}\right)\right]+n_{j}
$$

Where $w_{j}=\frac{2 n_{j}}{T}, j=1,2, \ldots n ; n_{j}$ are the residual terms and $w_{j}$ denotes Fourier frequencies and $1\left(w_{j}\right)$ represents the periodogram of a time series $r_{1}$ and defined as

$l\left(w_{j}\right)=\frac{1}{2 \pi T}\left|\sum_{t=1}^{T} r_{1} e^{-w_{j} t}\right|^{2}$ 


\subsubsection{GPS Test}

The Gaussian semi-parametric estimate proposed by Robinson and Henry (37) is based on the whittle approximation maximum likelihood estimator. GPS estimator can be written as;

$$
\hat{d}_{G P S}=\arg \min _{d} R(d)
$$

Where $R(d)=\log \left(\frac{1}{m} \sum_{j=1}^{m} \lambda_{j}{ }^{2 d} I\left(\lambda_{j}\right)\right)-\frac{2 d}{m} \sum_{j-1}^{m} \log \lambda_{j}$, $m$ represents the bandwidth, which increase with the sample size T.I $\left(\lambda_{j}\right)$ denotes the periodogram and $\lambda_{j}=2 \pi j / T$.

\subsection{Data for the Study}

The series used in the data analysis include three Agricultural market indices: wheat, sorghum and rice. Major producers of these cereal crops include: United States, Nigeria, India, Mexico, and Argentina, especially sorghum. These countries have been top producing countries for wheat, sorghum, and rice, according to the Food and Agriculture Organization (38). Also, the market classification as emerging is based on Morgan Stanley Capital International (MSCI). It is said that an emerging market (or an emerging country or an emerging economy) is a market that has certain characteristics of a developed market but does not fully comply with its standards. Sharad and MouSuMi (12) note that the Morgan Stanley Capital International (MSCI) market classification scheme depends on the following three criteria: size and liquidity, economic development, and market accessibility. However, the present study uses agricultural commodity prices data which were collected from https://www.indexmundi.com/agriculture/. The data extracted spanned from September, 1990 to 30th August, 2020, making a total of 1080 data points used in the study. The monthly closing values of the individual indices were taken and monthly logarithmic index returns were calculated using

$R I=\log \left(\frac{\mathrm{AS}_{\mathrm{t}}}{A S_{t-1}}\right) \times 100$

Where $\mathrm{AS}_{\mathrm{t}}$ represents prices of agricultural produce series at time "t" and $A S_{t-1}$ represents prices of agricultural produce at time lagged " $t-1$ ". In statistical analysis of the dynamics of price, we usually use logarithm of the price at the present time divide by the previous time (the lagged). Similarly, square returns on the agricultural commodity markets price series is defined thus:

$$
\text { Square Returns }=R I^{2}
$$

Also, absolute returns on the agricultural commodity markets price series is defined as thus :

$$
\text { Absolute } \operatorname{Re} \text { turns }=|R I|
$$

Return on price innovations are used because prices of stock are usually correlated and when there is the presence of correlation in a variable, it leads to biased estimation. Similarly, prices could also be non-stationary and have trends which may not conform to volatility clustering as one of the characteristics of data that violate the assumption of homoskedasticity. We test for long memory on raw, continuous return, absolute return (mod value) and squared return series from the emerging agricultural markets referred above and the software used for data Analysis was STATA version 15

\section{RESULTS}

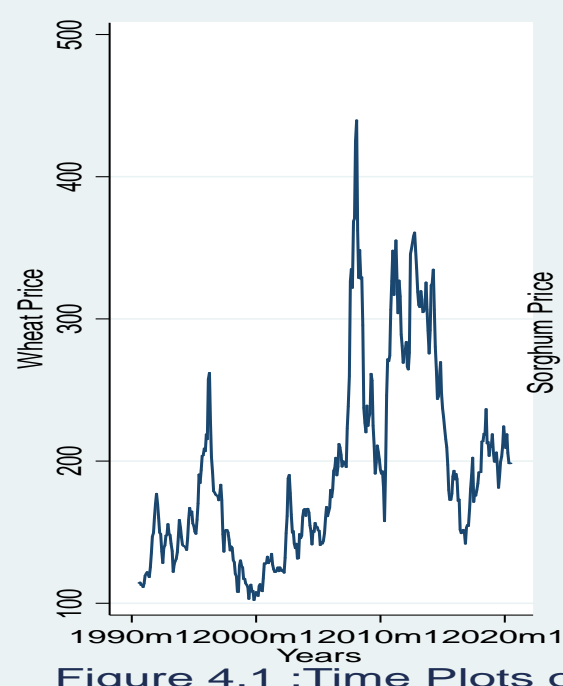

Figure 4.1 :Time plots on the three Raw

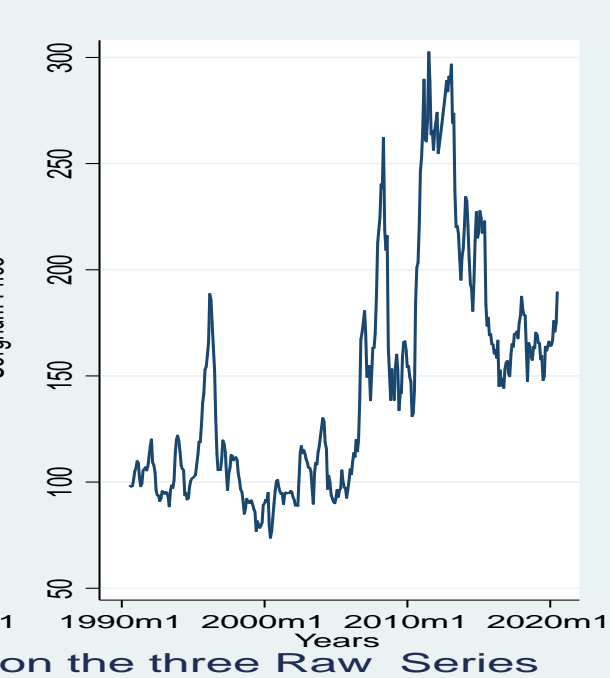

Series

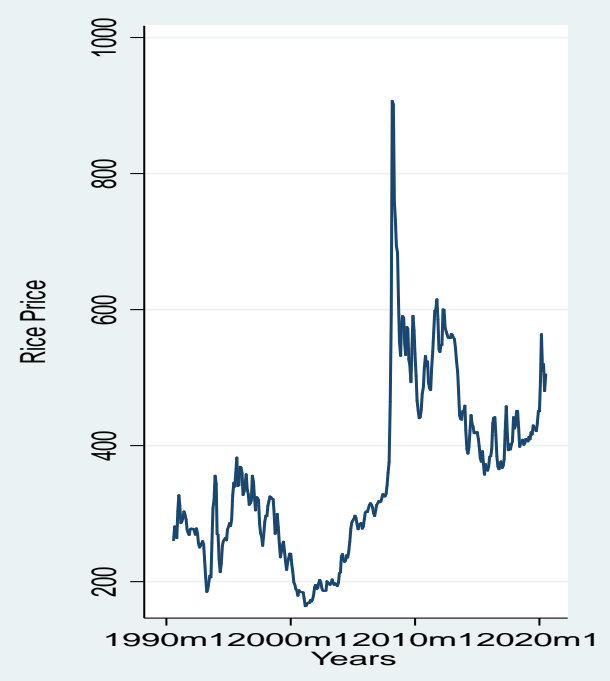



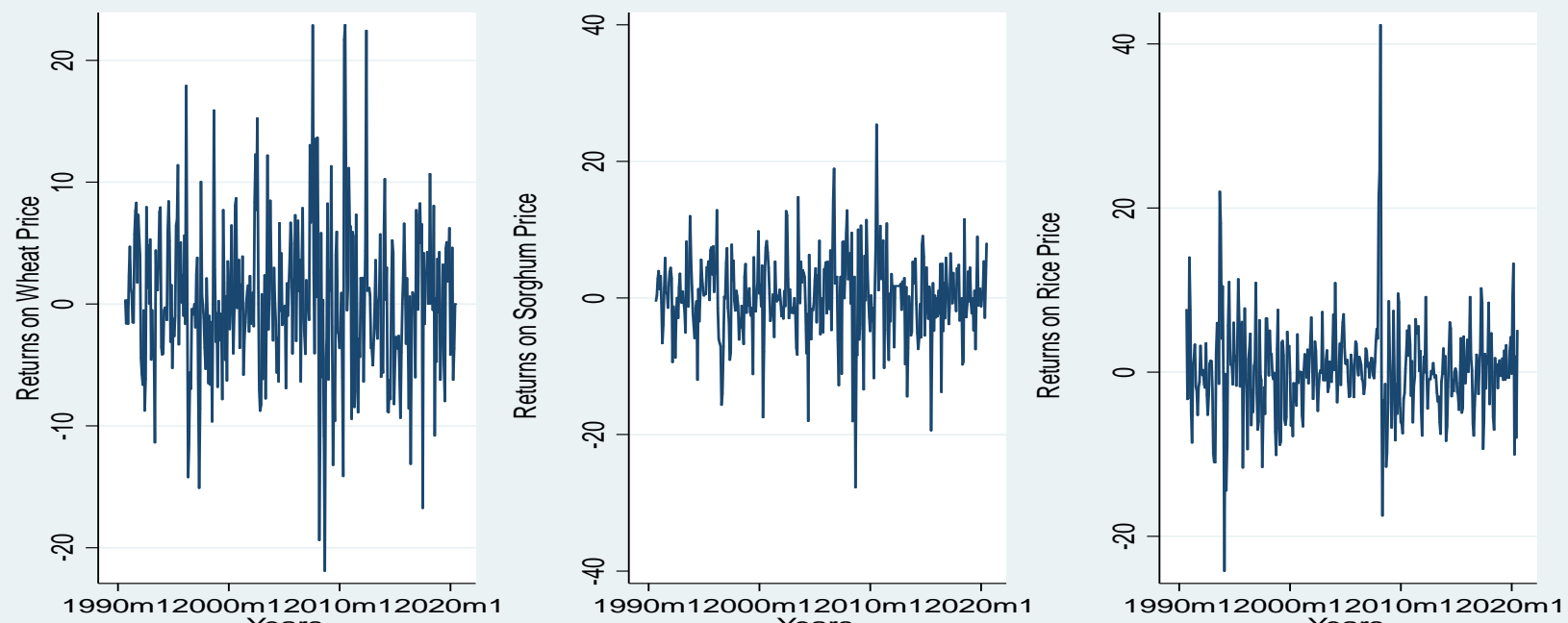

Figure 4.2: Time Plots on the Returns on the three Years
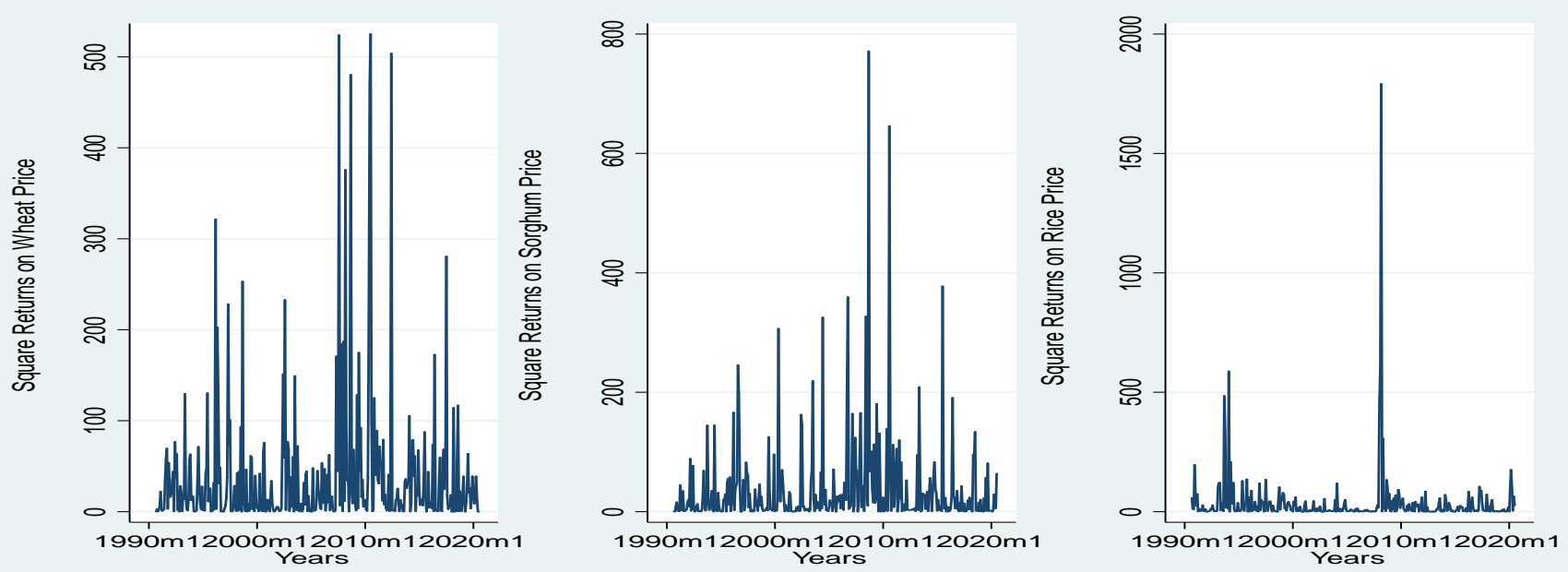

Figure 4.3: Time Plots on Square Returns in the three Series
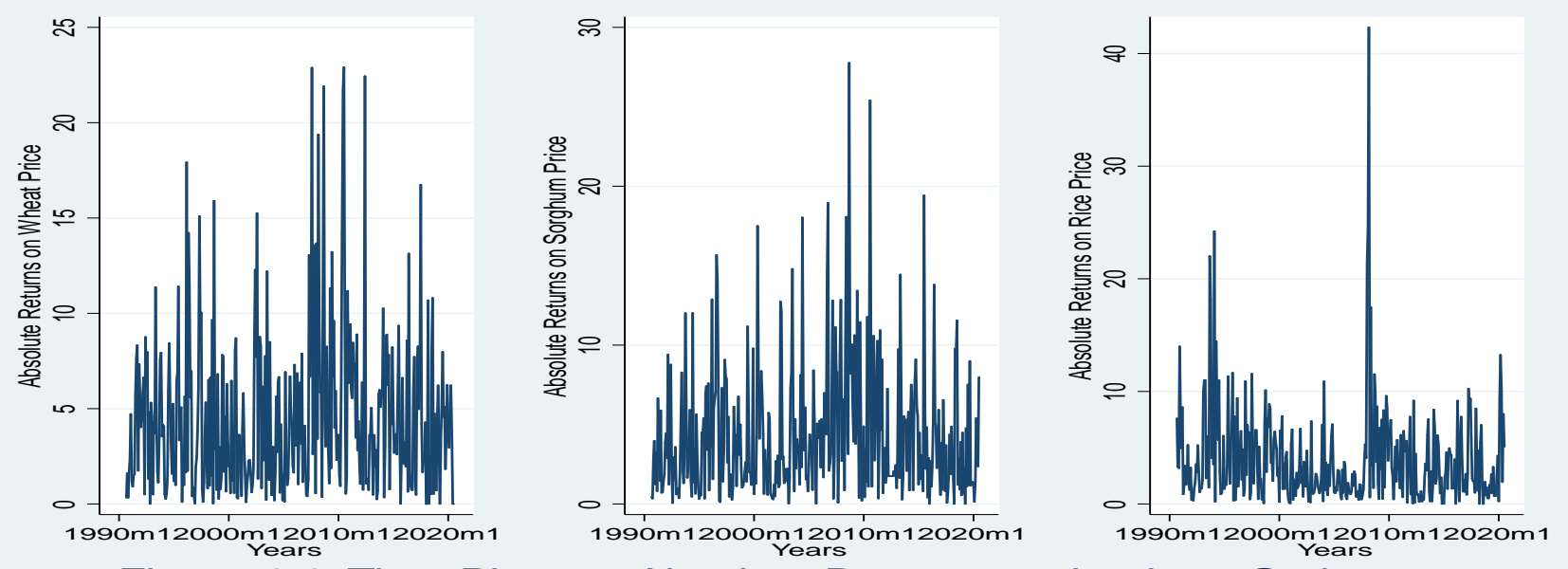

Figure 4.4: Time plots on Absolute Returns on the three Series 

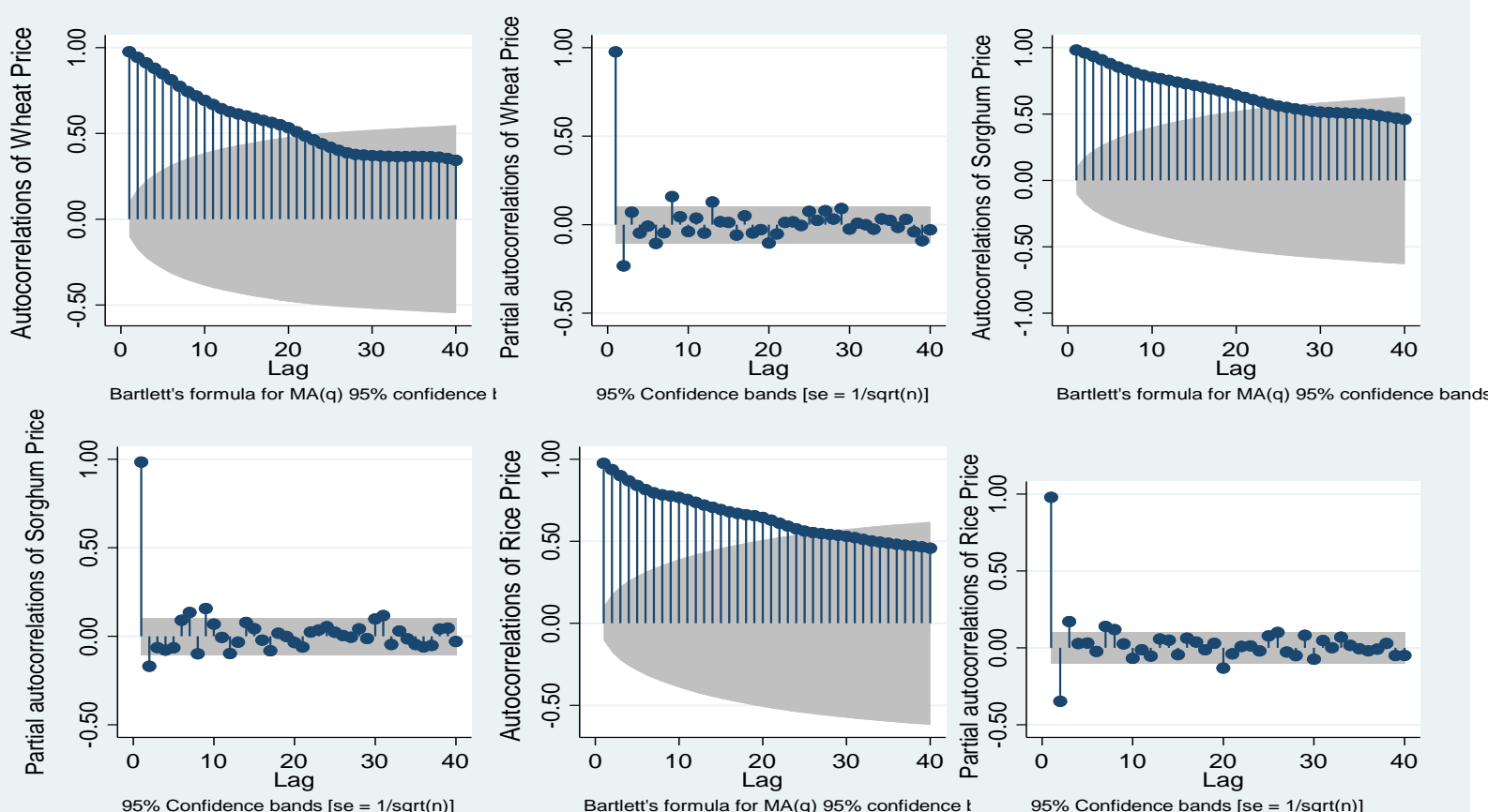

Figure 4.5: ACF and PACF Plots on the three Raw Series
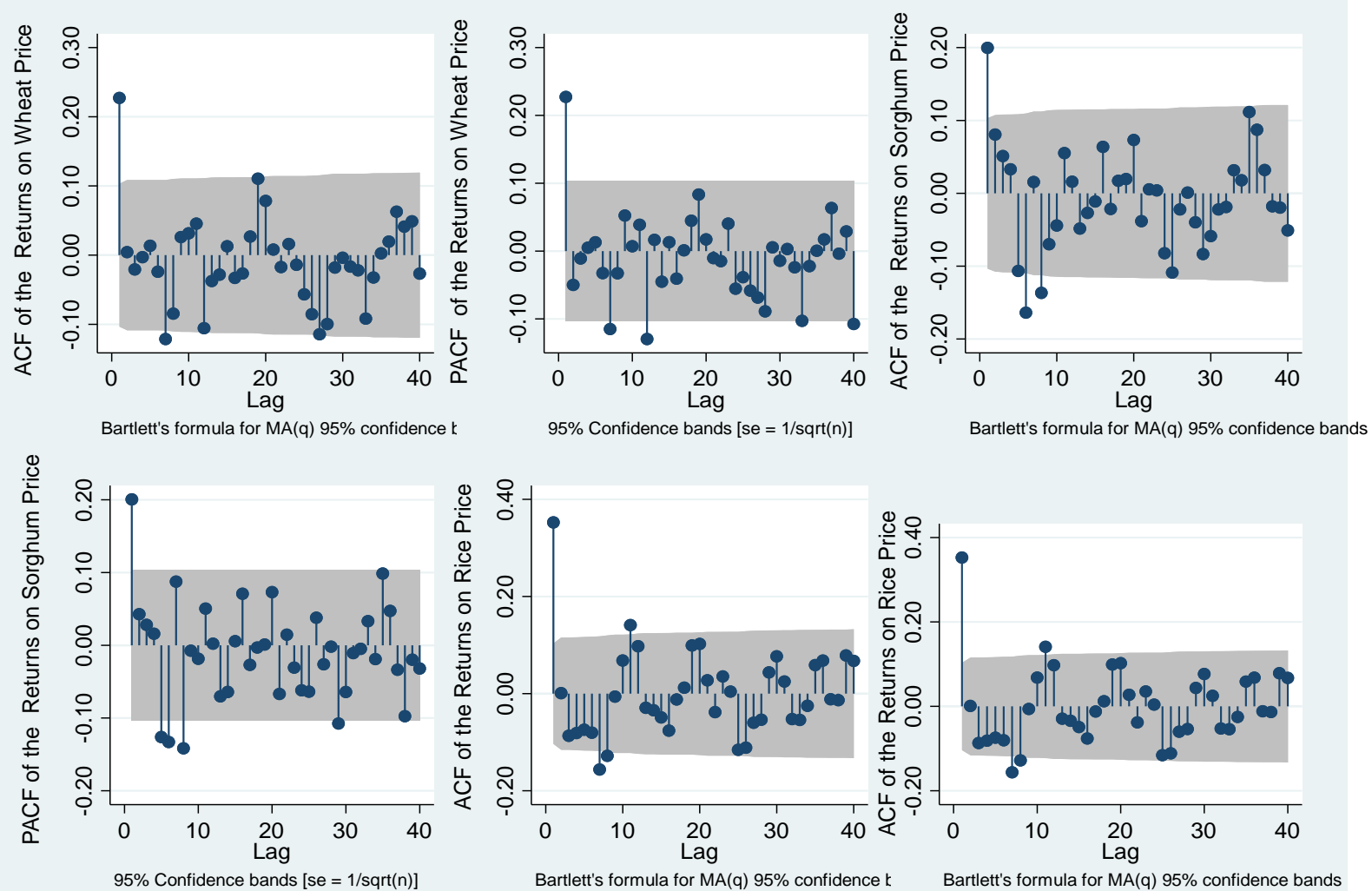

Figure 4.6: ACF and PACF of the Returns on three Price Series 


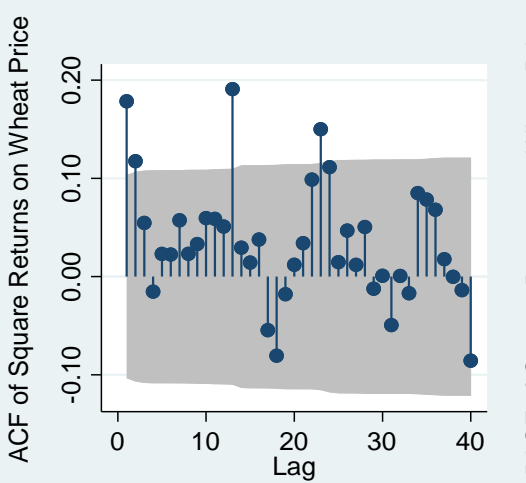

D) Bartlett's formula for MA(q) $95 \%$ confidence $k$

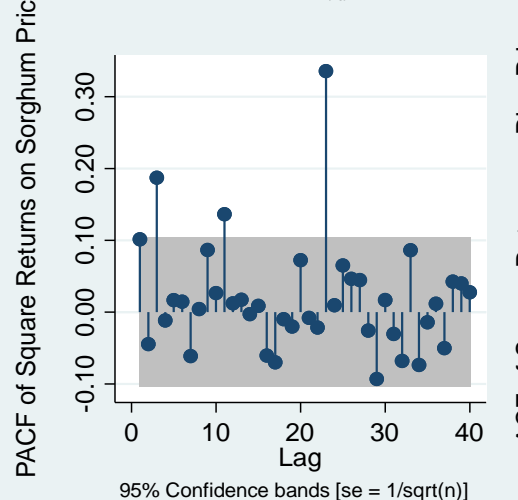

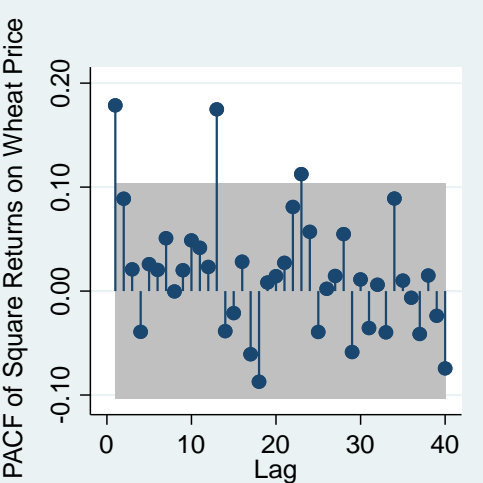

$95 \%$ Confidence bands [se $=1 /$ sqrt $(n)]$

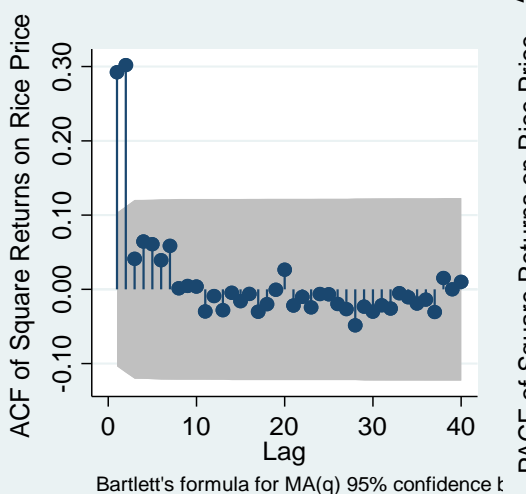

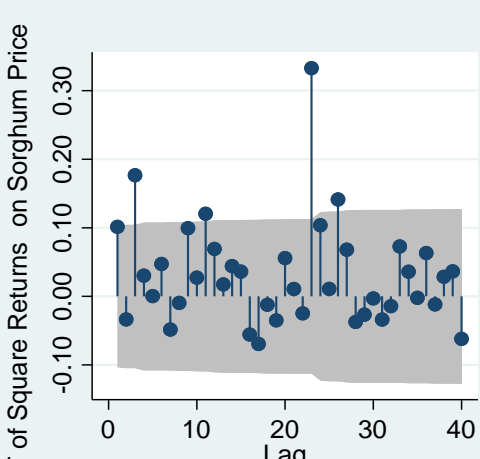

Bartlett's formula for MA(q) $95 \%$ confidence bands

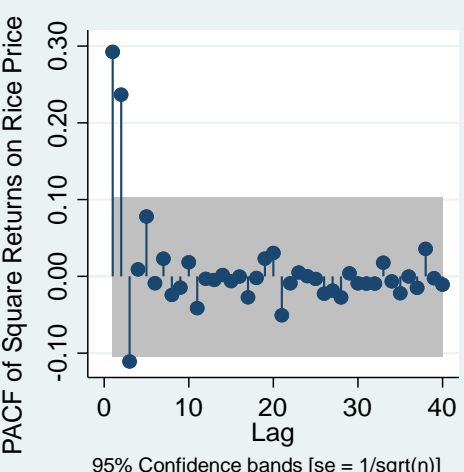

Figure 4.7: ACF \& PACF of the Square Returns on the three Price Series
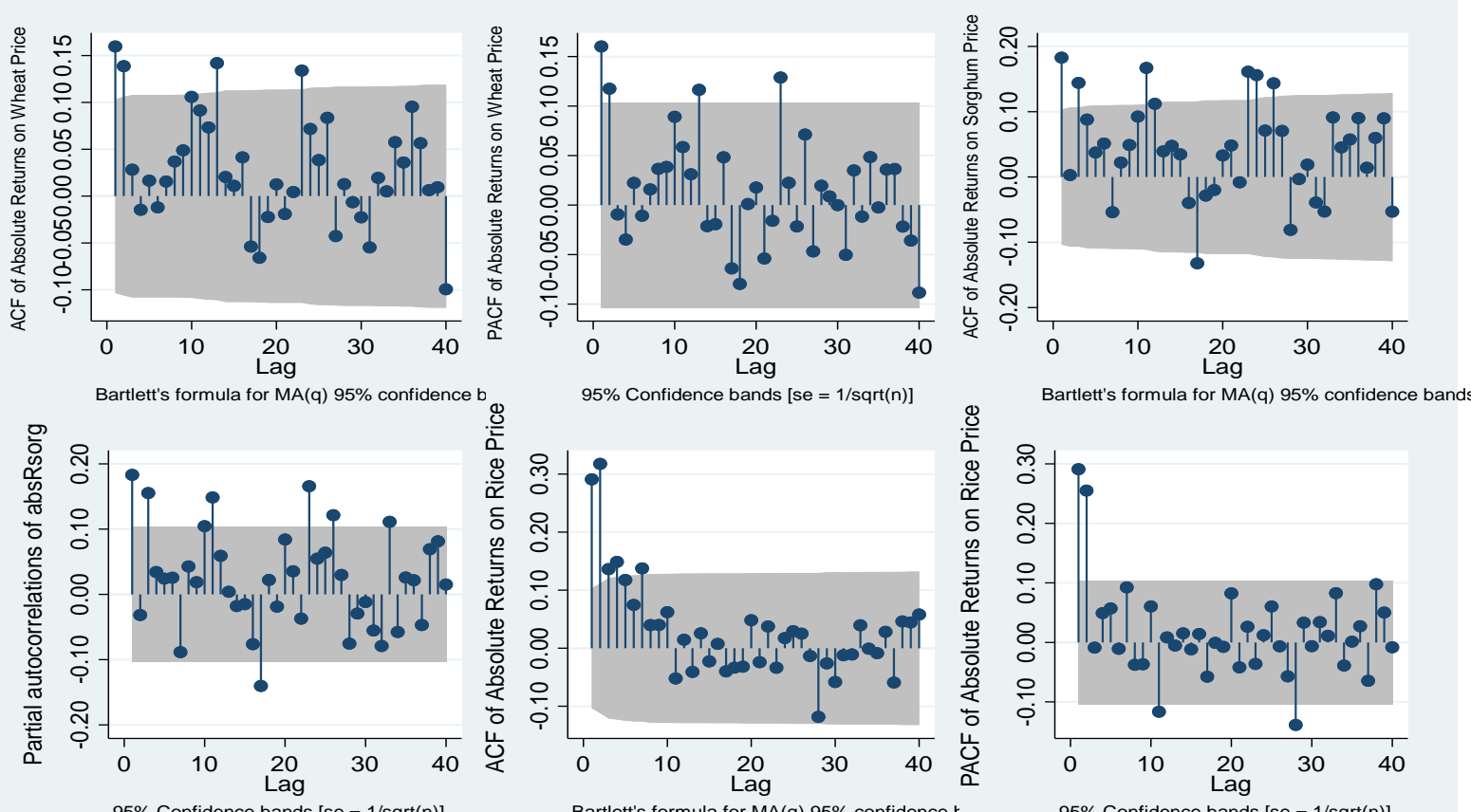

Bartlett's formula for MA(q) $95 \%$ confidence bands

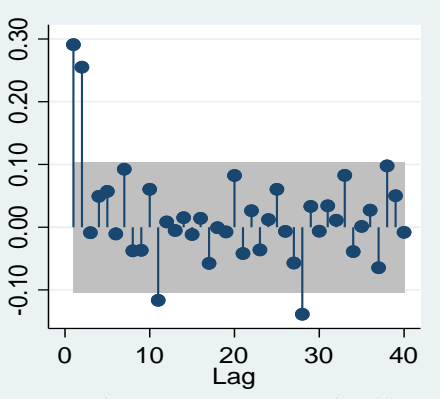

Figure 4.8: ACF \& PACF of the Absolute Returns on the three Price Series 
Table 4.1: Descriptive Statistics

\begin{tabular}{|c|c|c|c|c|c|c|c|c|c|c|}
\hline & $\begin{array}{l}\text { Return } \\
\text { Series }\end{array}$ & Mean & Median & Max & Min & S.D. & Skewness & Kurtosis & J-B & Prob \\
\hline \multirow[b]{3}{*}{ Raw } & Wheat & 192.596 & 176.070 & 439.720 & 102.160 & 68.378 & 1.050 & 3.439 & 69.022 & 0.000 \\
\hline & Sorghum & 145.708 & 129.385 & 302.530 & 73.720 & 55.346 & 0.977 & 3.084 & 57.401 & 0.000 \\
\hline & Rice & 355.666 & 324.750 & 907.000 & 163.750 & 129.836 & 0.865 & 3.920 & 57.631 & 0.000 \\
\hline \multirow{3}{*}{$\begin{array}{c}\text { Continuo } \\
\text { us } \\
\text { Return }\end{array}$} & Rwheat & 0.154 & 0.000 & 22.915 & -21.918 & 6.174 & 0.317 & 4.784 & 53.605 & 0.000 \\
\hline & Rsorg & 0.183 & 0.348 & 25.418 & -27.772 & 5.983 & -0.350 & 5.494 & 100.351 & 0.000 \\
\hline & Rrice & 0.184 & -0.046 & 42.326 & -24.242 & 5.795 & 1.266 & 12.518 & 1450.97 & 0.000 \\
\hline \multirow{3}{*}{$\begin{array}{l}\text { Square } \\
\text { Return }\end{array}$} & SqRwhat & 38.031 & 13.162 & 525.104 & 0.000 & 74.368 & 4.237 & 24.218 & 7808.639 & 0.000 \\
\hline & SqRsorg & 35.726 & 9.838 & 771.267 & 0.000 & 75.435 & 5.338 & 41.932 & 24377.20 & 0.000 \\
\hline & SqRrice & 33.522 & 6.704 & 1791.51 & 0.000 & 114.623 & 11.1747 & 159.661 & 374591. & 0.000 \\
\hline \multirow{3}{*}{$\begin{array}{l}\text { Absolute } \\
\text { Return }\end{array}$} & Absrwhat & 4.544 & 3.628 & 22.915 & 0.000 & 4.175 & 1.719 & 7.0108 & 417.391 & 0.000 \\
\hline & Absrsorg & 4.348 & 3.136 & 27.772 & 0.000 & 4.107 & 1.925 & 8.393 & 656.860 & 0.000 \\
\hline & Absrrice & 3.877 & 2.589 & 42.326 & 0.000 & 4.306 & 3.427 & 23.715 & 7121.556 & 0.000 \\
\hline
\end{tabular}

Table 4.2: Unit Root Test for Stationarity at First Difference

\begin{tabular}{|c|c|c|c|c|c|c|c|c|c|c|c|c|}
\hline \multirow{2}{*}{ Price(s) } & \multicolumn{4}{|c|}{ Augmented Dickey Fuller Test (ADFT) } & \multicolumn{4}{|c|}{ Phillip PerronTest (PPT) } & & \multicolumn{3}{|c|}{ KPSS Test } \\
\hline & $\begin{array}{l}\text { Test } \\
\text { Stat }\end{array}$ & & & & $\begin{array}{l}\text { Test } \\
\text { Stat }\end{array}$ & & & & $\begin{array}{l}\text { Test } \\
\text { Stat }\end{array}$ & & & \\
\hline & & $1 \%$ & $5 \%$ & $10 \%$ & & $1 \%$ & $5 \%$ & $10 \%$ & & $1 \%$ & $5 \%$ & $10 \%$ \\
\hline Wheat & -12.820 & -2.337 & -1.649 & -1.284 & 0.468 & 0.216 & 0.176 & 0.119 & 0.467 & 0.216 & 0.146 & 0.119 \\
\hline Sorgh & -11.517 & -2.337 & -1.649 & -1.284 & 0.468 & 0.216 & 0.176 & 0.119 & 0.474 & 0.216 & 0.146 & 0.119 \\
\hline Rice & -13.135 & -2.33 & -1.649 & -1.284 & 0.468 & 0.216 & 0.176 & 0.119 & 0.485 & 0.216 & 0.146 & 0.119 \\
\hline
\end{tabular}

(a) The test statistic critical values owe those of mackinnon (1991)

Table 4.3: Hurst - Mandelbort's Classical Rescale and Lo’s Statistics Estimates for the Test of the Presence of Long Memory

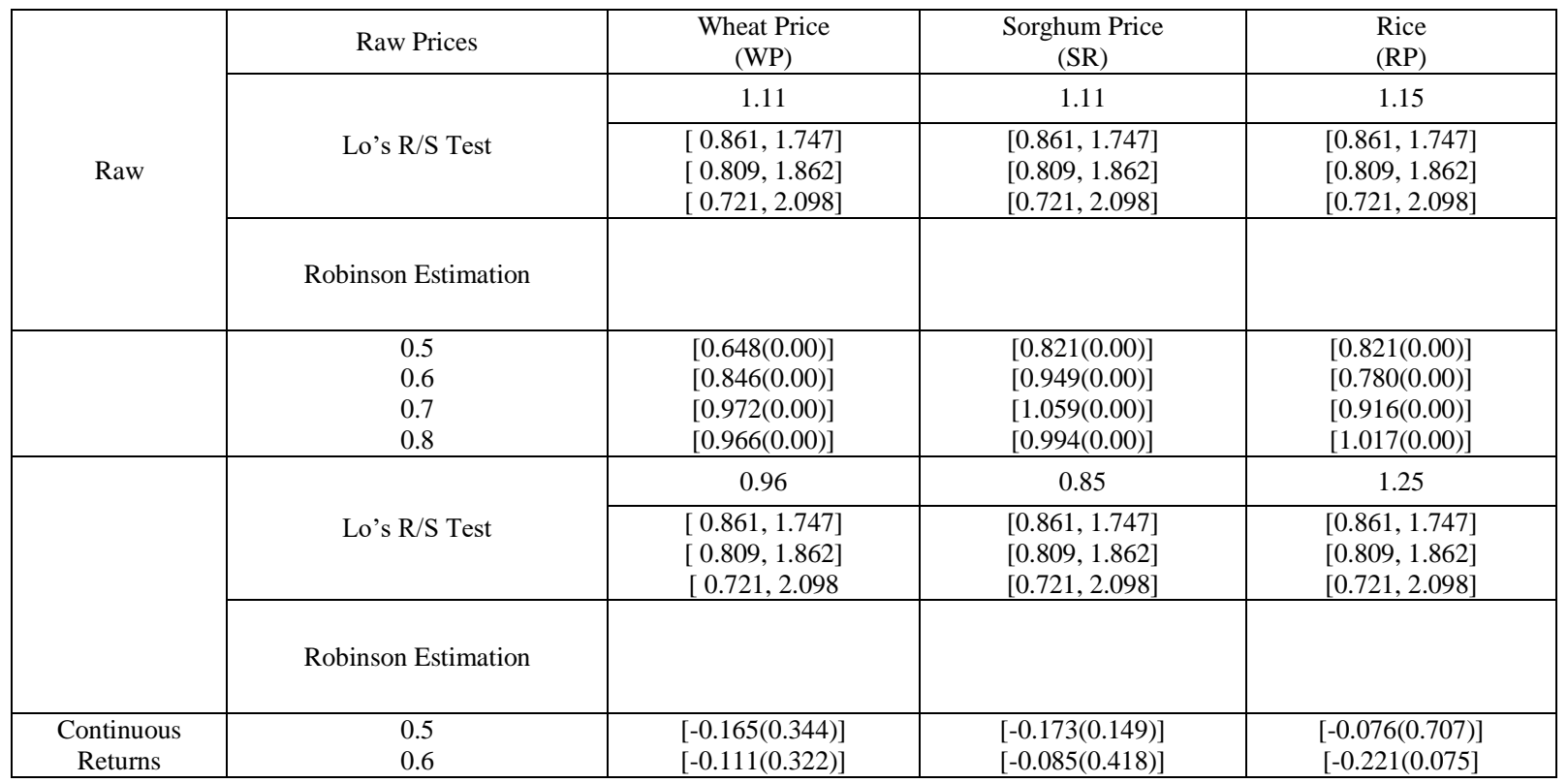




\begin{tabular}{|c|c|c|c|c|}
\hline & $\begin{array}{l}0.7 \\
0.8 \\
\end{array}$ & $\begin{array}{l}{[0.038(0.715)]} \\
{[0.085(0.218)]} \\
\end{array}$ & $\begin{array}{l}{[0.108(0.243)]} \\
{[0.071(0.254)]} \\
\end{array}$ & $\begin{array}{l}{[-0.063(0.493)]} \\
{[0.024(0.691)]} \\
\end{array}$ \\
\hline & \multirow{2}{*}{ Lo's R/S Test } & 1.90 & 1.89 & 1.00 \\
\hline \multirow{3}{*}{ Square Returns } & & $\begin{array}{l}{[0.861,1.747]} \\
{[0.809,1.862]} \\
{[0.721,2.098]}\end{array}$ & $\begin{array}{c}{[0.86,1.747]} \\
{[0.809,1.862]} \\
{[0.721,2.098]}\end{array}$ & $\begin{array}{l}{[0.861,1.747]} \\
{[0.809,1.862]} \\
{[0.721,2.098]}\end{array}$ \\
\hline & Robinson Estimation & & & \\
\hline & $\begin{array}{l}0.5 \\
0.6 \\
0.7 \\
0.8 \\
\end{array}$ & $\begin{array}{l}{[0.276(0.054)]} \\
{[0.169(0.089)]} \\
{[0.137(0.053)]} \\
{[0.180(0.001)]}\end{array}$ & $\begin{array}{l}{[0.243(0.135)]} \\
{[0.164(0.168)]} \\
{[0.205(0.010)]} \\
{[0.092(0.156)]}\end{array}$ & $\begin{array}{c}{[-0.316(0.074)]} \\
{[-0.94(0.358)]} \\
{[0.051(0.415)]} \\
{[0.264(0.000)]}\end{array}$ \\
\hline \multirow{4}{*}{$\begin{array}{l}\text { Absolute } \\
\text { Returns }\end{array}$} & & 1.87 & 1.86 & 1.57 \\
\hline & Lo's R/S Test & $\begin{array}{l}{[0.861,1.747]} \\
{[0.809,1.862]} \\
{[0.721,2.098]}\end{array}$ & $\begin{array}{c}{[0.86,1.747]} \\
{[0.809,1.862]} \\
{[0.721,2.098} \\
\end{array}$ & $\begin{array}{l}{[0.861,1.747]} \\
{[0.809,1.862]} \\
{[0.721,2.098]}\end{array}$ \\
\hline & Robinson Estimation & & & \\
\hline & $\begin{array}{l}0.5 \\
0.6 \\
0.7 \\
0.8 \\
\end{array}$ & $\begin{array}{l}{[0.298(0.055)]} \\
{[0.277(0.050)]} \\
{[0.171(0.059)]} \\
{[0.172(0.004)]}\end{array}$ & $\begin{array}{l}{[0.307(0.037)]} \\
{[0.275(0.023)]} \\
{[0.280(0.001)]} \\
{[0.108(0.070)]}\end{array}$ & $\begin{array}{l}{[0.144(0.441)]} \\
{[0.227(0.036)]} \\
{[0.369(0.000)]} \\
{[0.331(0.000)]}\end{array}$ \\
\hline
\end{tabular}

The estimated values of the long memory parameters were all tested at $1 \%$, 5\% and 10\% level of Significance respectively and the values in the bracket " ()"represents estimated probability

Table 4.4: GPH Estimation of the Fractional Differencing Parameter (D)

\begin{tabular}{|c|c|c|c|c|}
\hline & Indices & Wheat price & Sorghum price & Rice price \\
\hline \multirow{4}{*}{ Raw } & $\mathrm{M}=\mathrm{T}^{0.5}$ & $0.675(0.001)$ & $0.087(0.000)$ & $0.858(0.000)$ \\
\hline & $\mathrm{M}=\mathrm{T}^{0.6}$ & $0.875(0.000)$ & $0.955(0.00)$ & $0.802(0.000)$ \\
\hline & $\mathrm{M}=\mathrm{T}^{0.7}$ & $0.983(0.000)$ & $1.069(0.000)$ & $0.927(0.000)$ \\
\hline & $\mathrm{M}=\mathrm{T}^{0.8}$ & $1.010(0.000)$ & $1.041(0.000)$ & $1.049(0.000)$ \\
\hline \multirow{5}{*}{$\begin{array}{c}\text { Continuous Returns } \\
\text { Series }\end{array}$} & & RWheat & Rsorghum & RRice \\
\hline & $\mathrm{M}=\mathrm{T}^{0.5}$ & $-0.159(0.413)$ & $-0.173(0.373)$ & $0.014(0.942)$ \\
\hline & $\mathrm{M}=\mathrm{T}^{0.6}$ & $-0.083(0.525)$ & $-0.095(0.464)$ & $0.200(0.125)$ \\
\hline & $\mathrm{M}=\mathrm{T}^{0.7}$ & $0.037(0.688)$ & $0.108(0.247)$ & $-0.065(0.482)$ \\
\hline & $\mathrm{M}=\mathrm{T}^{0.8}$ & $0.095(0.168)$ & $0.081(0.288)$ & $0.021(0.761)$ \\
\hline \multirow{5}{*}{$\begin{array}{l}\text { Square Returns On } \\
\text { Prices }\end{array}$} & & SQRWheat & SQRSorghum & SQRrice \\
\hline & $\mathrm{M}=\mathrm{T}^{0.5}$ & $0.300(0.122)$ & $0.252(0.195)$ & $-0.312(0.108)$ \\
\hline & $\mathrm{M}=\mathrm{T}^{0.6}$ & $0.149(0.254)$ & $0.183(0.160)$ & $-0.087(0.504)$ \\
\hline & $\mathrm{M}=\mathrm{T}^{0.7}$ & $0.140(0.131)$ & $0.207(0.026)$ & $0.050(0.591)$ \\
\hline & $\mathrm{M}=\mathrm{T}^{0.8}$ & $0.195(0.004)$ & $0.106(0.123)$ & $0.266(0.000)$ \\
\hline $\begin{array}{c}\text { Absolute Returns On } \\
\text { Prices }\end{array}$ & & AbWheat & Absorghum & Abrice \\
\hline
\end{tabular}




\begin{tabular}{|l|l|l|l|l|}
\hline \multirow{3}{*}{} & $\mathrm{M}=\mathrm{T}^{0.5}$ & $0.336(0.084)$ & $0.304(0.117)$ & $0.178(0.358)$ \\
\cline { 2 - 5 } & $\mathrm{M}=\mathrm{T}^{0.6}$ & $0.211(0.105)$ & $0.290(0.026)$ & $0.248(0.057)$ \\
\cline { 2 - 5 } & $\mathrm{M}=\mathrm{T}^{0.7}$ & $0.211(0.105)$ & $0.284(0.002)$ & $0.371(0.000)$ \\
\cline { 2 - 5 } & $\mathrm{M}=\mathrm{T}^{0.8}$ & $0.189(0.006)$ & $0.122(0.076)$ & $0.347(0.000)$ \\
\hline
\end{tabular}

The estimated values of the fractional differencing parameter $(D)$ were all tested at $1 \%, 5 \%$ and $10 \%$ level of Significance respectively and the values in the bracket "()"represents estimated probability

\section{DISCUSSION}

\subsection{Visual Interpretation of the Time Plots on the three Series}

The time plot from emerging agricultural markets is presented in Figures 4.1. This figure indicates an anticipated nonstationary method that exists in the price series. The series shows a continuous trend across the vertical axis of the time of the observations (data series) while the time is on the horizontal axis. Figure 4.2, 4.3 and 4.4 also illustrate the time plot or data series on 100 percent returns on prices in emerging agricultural markets (RIT). There are clustering effects in the return series from physical observation, a period of high volatility followed by a period of tranquility, such that future returns from Nigerian international markets fluctuate in a range smaller than the normal distribution. These are some circumstances where a certain commodity futures return, conforming to Roengchai's (39) assertion, oscillates on a very wide scale, which a normal distribution allows. This process is important, according to Mohammad Saeid (40), in order to recognize the distribution of data and prepare the financial services for the modeling process in a way.

\subsection{Visual Interpretation of the Autocorrelation Function $(A C F)$ and Partial Correlation Function (PACF) for the} three Series

Figure 4.5 to 4.8 show the ACF and PACF plots for the raw data, continuous return, absolute return and squared return series of all the three indices. The ACF was plotted against the time lag of the series for all the three indices under investigation. There was a lag of up to one month and ten days (40).The raw data of all the indices, from visual examination of autocorrelation delay rate, show that there is the presence of long memory in the monthly returns in the emerging agricultural markets. Figure 4.5, 4.6, 4.7 and 4.8 shows the autocorrelation function of an emerging agricultural markets monthly returns and the graphs show that the autocorrelation is persistent and significant at 26, 23 and 24 lags respectively. This is evidence of non-stationary series since they fall outside the $95 \%$ confidence interval while their partial autocorrelation function as shown in figure 4.5, 4.6, 4.7 and 4.8 ,cut off at 2,2 , and 4 respectively. The autocorrelation function (ACF) tails off, showing significant spikes at their respective lags while the partial autocorrelation function showing a positive first lag and a set of exponential decays is an indication of an AutoRegressionAR(P) process using the correlogram table as a crude. Otherwise, if the first lag of the Autocorrelation function of the difference shows a cut-off and/or the first lag is negative, then it is expected to add Moving Average (MA) terms to the model. The findings also support the existence of the Taylor Effect in the emerging agricultural markets, as absolute returns autocorrelations (Figure 4.8) are generally greater than those of squared returns (Figure 4.7).

\subsection{Descriptive Statistic}

Table 4.1 contains the descriptive statistical properties, raw data, continuous return, squared return, and absolute returns on prices of three agricultural produce wheat, sorghum, and rice, from emerging agricultural markets. The returns show that the average (mean) of all the series is positive and it was also found that the highest mean returns are for raw data as thus: wheat (192.596), sorghum (145.708) and Rice (355.666); followed by square returns having mean values; sqrwheat (38.031), sqrghum (35.726), sqrrice (33.522), next is absolute return series with mean returns; Abswheat(4.548). Abssorghum (4.347) and Abrice (3.877); and continuous returns with mean returns of $(0.184)$ for returns on the price of rice, $(0.183)$ for returns on the price of sorghum, and that of returns on the price of wheat (0.514). Similarly, their standard deviations also follow that order except for the case of continuous returns series that is higher than the standard deviation of the absolute returns series.

In another development, the raw series, continuous return, squared and absolute returns on the price series are all positively skewed to the right, except the case of continuous returns on the price of sorghum $(-0.350)$ that is negatively skewed to the left. However, from all indications, the four series appear to be leptokurtic. The values of the kurtosis suggested that the raw, continuous return, squared and absolute return series cannot be concluded that they are normally distributed.

\section{$5.4 \quad$ Unit Root Test}

Table 4.2 contains the results for unit root tests, using Augmented Dickey-fuller, Phillip perron, and Kwiatkowski Phillips Schmidt and Shin (KPSS) test. The null hypotheses of unit root with drift were tested at a 5\% level of significance, following Lee, et al (40) test statistic critical value. The results show that the Augmented Dukey-fuller test statistics are stationary since it rejects the null hypotheses at a 5\% level of significance following Lee, et al (40) test statistic critical value. Also, the KPSS test statistics shows that series is significant to reject the null hypothesis of non-stationarity at a 5\% level of significance. In most, cases these tests usually 
give the same solution for price related series data. However, for the data which suffered from the effect of external factors such as natural disaster, crises and external environmental factors as mentioned in many studies these tests may also give the adverse solutions due to the effects of the long memory. Lee, et al (40) in their study on the application of the long memory model to model German stock returns mentioned that the KPSS test fails to reject the alternative unit root test process when there is the presence of long memory in a data series. Although, Lee, et al (40) reveal that other unit root test can also be applied to the data which contains long memory.

\subsection{Resealed-Range $(R / S)$ Analysis Results using Hurst- Mandelbrot's Classical R/S Statistic and Lo's Test Statistics}

The results for Rescaled - Range (R/S) Analysis using Hurst Mandelbrot's classical R/S statistic and Lo's test statistics for raw series, continuous returns, squared returns, and absolute returns are displayed in table 4.4. The estimated values obtained from Hurst-Mandelbrot's classical R/S statistics revealed that the null hypothesis of no long-range dependence in all cases, for raw series using all the classes of the returns, cannot be rejected at a generally acceptable level of significance. This is because all estimated values of the test statistics fall within the acceptance region. Although, this is also applicable to squared and absolute returns on wheat and sorghum price whereas the case of continuous returns series is different. Similarly, Lo's test statistics was also computed since classical rescaled- range statistic is sensitive to shortmemory properties and is capable of giving biased results in the case of short-range dependence and heterogeneities (40). The Lo's test statistics also confirmed that the null hypothesis of no long-range dependence in the case of all seventeen indices could not be repeated at a generally acceptable level of significance as the estimated value of the statistics falls within the acceptance region. The critical value of the statistics used in this study is obtained in line with Lo (35)Table 11,. The facts from all indicators show that the raw series and squared returns on prices of wheat and sorghum have evidence of the presence of long memory behavior. These results agree with characteristics for short memory for continuous return series and a long memory for estimating volatility in general for selected prices in emerging agricultural stock markets.

\subsection{Geweke and Porter-Hudak (GPH) Estimates for Fractional Differencing Parameter (d)}

Table 4.4 contains estimates of the fractional differencing parameter(d) for raw series, continuous returns, squared returns and absolute return series of all three indices from emerging agricultural stock markets. The GPH test examines the null hypothesis of short-range dependence $\left(\mathrm{H}_{0}: \mathrm{d}=0\right)$ versus the long memory alternative $\left(\mathrm{H}_{1}: \mathrm{d}=0\right)$ for a range of bandwidth $\left(M=T^{0.5}, T^{0.6}, T^{0.7}\right.$, and $\left.T^{0.8}\right)$. The estimates of $d$ are statistically significant for all the three indices in the raw series. The null hypothesis of the presence of short memory is rejected while the alternative confirmed that long memory exists in the raw series and volatility in the returns of prices in selected agricultural stock markets. Estimate (d) is confirmed to be statistically significant for one chosen bandwidth $\left(\mathrm{M}=\mathrm{T}^{0.8}\right)$ in the squared returns on prices of wheat and rice respectively. Similarly, it is also confirmed that the estimates $\mathrm{d}$ is significant at a $1 \%$ level of significance for two chosen bandwidths $\left(\mathrm{M}=\mathrm{T}^{0.7}\right.$ and $\left.\mathrm{T}^{0.8}\right)$ in the absolute returns on all the series and these show evidence of mixed estimates in this case. However, the parameter values obtained from the spectral technique show the presence of long memory as their values lie within the theoretical value $(0.5<\mathrm{d}<1.05)$ for the raw series and absolute returns on price, series whereas for the case of continuous return series, it lies within the theoretical value $(-0.2<\mathrm{d}<0.5)$ and all the various levels of periodogram ordinates used in this present study. The values of the parameters are significant at $1 \%, 5 \%$, and $25 \%$ confidence level.

\section{CONCLUSION}

The study investigates properties of Long Memory in return innovations from emerging agricultural markets. The aim is to determine the presence of long memory properties in emerging agricultural markets' return innovations, using Hurst-Classical Mandelbrot's R/S statistics, Lo's statistics, and semi-parametric GPH statistics. The data used in the analysis includes three Agricultural market indices: wheat, sorghum and rice. The data was extracted from https://www.indexmundi.com/agriculture/ and it spanned from September 1990 to 30th September 2020 making a total of 1080 data points used in the study. From the results of the findings, it was confirmed that the study was in line with the Taylor effect, as the autocorrelations of the absolute returns are greater than those of the squared returns. Also, the estimates of absolute returns fractional differentiating parameter (d) are greater than that of the squared returns. From all indications, there was no presence of long-term memory in the continuous market returns, indicating that the emerging agricultural market returns follow a random walking process. Furthermore, in the continuous return series of the indices, the absence of long memory did not show any evidence against the weak form of market efficiency in the returns on price in the emerging agricultural market.Lack of long memory in this case simply implies that agricultural produce from these markets were not systematically overvalued or under-valued, justifying the inactive investment in the agricultural sector (index). In this case, investors can expect a normal rate of return (risk-adjusted) while agriculturists should expect to receive a fair value for the products they sell. Obviously, since past price patterns for future prices are not predictive, it leaves little or no scope for profitable opportunities for arbitration. The presence of long memory in squared returns indicates that asset return volatility can be modeled using recent as well as remote past returns and can therefore now be more efficiently priced for derivative instruments. The use of risk analysis models to estimate potential losses, which is the case of Value at Risk $(\mathrm{VaR})$. This is one of the important implications concerning 
the existence of long memory in an emerging agricultural market return series.

\section{REFERENCES}

[1] Naveen, M.. Modeling long range dependence in wheat Food Price Returns. International Journal of Economics and Finance. 2019,11(9),1916-9728

[2] Mandelbrot, B.B. \& Wallis, J. Robustness of the rescaled range $\mathrm{R} / \mathrm{S}$ in the measurement of non-cyclic long run statistical dependence. Water Resources Research, 1968, 5, 967-988

[3] Ding, Z., Granger, C. W. J., \& Engle, R. F. . A long memory property of stock market returns and a new model. Journal of Empirical Finance, 1993. 1(1), 83-106

[4] Andersen, T. G., \&Bollerslev, T. Heterogeneous information arrivals and return volatility dynamics: uncovering the long-run in high frequency returns. Journal of Finance, 1997. 52(3), 9751005.

[5] Andersen, T. G., \&Bollerslev, T. Answering the skeptics: yes, standard volatility models do provide accurate forecasts. International Economic Review, 1998. 39(4), 885-905.

[6] Breidt, F. J., Crato, N., \& de Lima, P.. On the detection and estimation of long memory in stochastic volatility. Journal of Econometrics, 1998, 83(1/2), 325-348

[7] Harvey, A. C. Long memory in stochastic volatility. In J. Knight, \& S. Satchell (Eds.), Forecasting Volatility in Financial Markets. 1993,307-320). Oxford, UK. Butterworth-Haineman.

[8] Liow, K.H., "The dynamics of return volatility and systematic risk in international real estate markets", Working paper, Department of Real Estate, National University of Singapore, 2006

[9] Pérez, A and Esther Ruiz, E. Finite sample properties of a $Q M L$ estimator of stochastic volatility models with long memory.2001, 70(2), 0-164. doi:10.1016/s0165-1

[10] Granger, C.W.J., Hyung, N., 2004. Occasional structural breaks and long memory with an application tothe S\&P 500 absolute stock returns. Journal of Empirical Finance 11, 399-421

[11] Banerjee. A; andUrga, G. Modelling structural breaks, long memory and stock market volatility: an overview. , 2005, 129(1-2), 1-34. doi:10.1016/j.jeconom.2004.09.001

[12] Sharad. N, B, and Mousumi B. Long Memory in Stock Returns: A Study of Emerging Markets.2012, Iranian Journal of Management Studies (IJMS) 67-88

[13] Brooks, Introductory Econometrics for Finance, 2008. DOI: 10.1017/CBO9780511841644

[14] Enrico,V, J. E. Essays in Long Memory. Institute for Okonomi, Aarhus University et.http://pure.au.dk/portal/files/104275540/J_ PhD_dissertation.pdf

[15] Franke, J., Kreiss, J., Mammen, E. and Neumann, M. Properties Of The Nonparametric Autoregressive Bootstrap, Journal of Time Series Analysis , 2003, 23: 555-585

[16] Eduardo V, Temperature anomalies, Long memory, and aggregation,2020. Department of Economics and Business Economics

[17] ChangyongF. HongyueW,Naiji. L,TianC,Hua, H, Ying, L, and Xin M. T. Log-transformation and its implications for data analysis, Shanghai Arch Psychiatry.2014, 26(2): 58-60. Doi: 10.3969/j.issn.1002-0829.2014.02.00

[18] Granger, C. W. J.. The typical spectral shape of an economic variable. Econometrica, 1966. 34(1), 150-161.

[19] Caporale, G.M., Gil-Alana, L.A., \&Plastun. O. Long memory and data frequency in financial markets. DIW Berlin discussion. 2017, 1647. https://dx.doi.org/10.2139/ssrn.2929524

[20] Hiremath, G.S., \&Kamaiah, B.. Long memory in stock market volatility: Indian evidences. ArthaVijnana, 2010.52(4),332345.https://doi.org/10.21648/arthavij/2010/v52/i4/115316
[21] Onour, I.A. North Africa stock markets: Analysis of long memory and persistence of shocks.InternationalJournal of Monetary Economics and Finance, $2010.23(2), \quad 101$ 111.https://doi.org/10.1504/JJMEF.2010.031231

[22] Christensen, B.J., Nielsen, M.O., \& Zhu, J. Long memory in stock market volatility and the volatility-in-mean effect: The FIEGARCH-M model. CREATES research paper:2007-10, University of

Aarhus, Denmark.https://doi.org/10.2139/ssrn.1150049

[23] Andersen, T.G., Bollerslev, T., Diebold, F.X., \&Labys, P. Modeling and forecasting realized volatility.Econometrica, 2003, 71(2),579-625. https://doi.org/10.1111/1468-0262.00418

[24] Jayasinghe, P., Tsui, A.K.C., \& Zhang, Z. New estimates of timevarying currency betas: A trivariate BEKK approach. Economic Modelling,42,128-139. https://doi.org/10.1016/j.econmod.2014.06.003।

[25] Stevenson, S.. An examination of volatility spilloversin REIT returns.Journal of Real Estate Portfolio Management, 2002, 8(3),229-238

[26] Wilson, P.J., \&Okunev, J. Long term dependencies and long run non-periodic co-cycles: Real estate and stock markets.Journal of Real Estate Research, 1999, 18(2), 257-278.

[27] Barkoulas, J., Labys, C.W., \&Onochie, J. Fractional dynamics in international commodity prices.Journal ofFutures Markets, 1997, 17(2),161-189.https//doi.org/10.1002/(SICI)10969934(199704)17:2<161::AID-FUT2>3.0.CO;2-H

[28] Kang, S.H., Kang, S.M., \& Yoon, S.M. Forecasting volatility of crude oil markets.Energy Economics, 2009, 31(1),119-125. https://doi.org/10.1016/j.eneco.2008.09.006

[29] Mann, J.M., Epperson, J., \& Escalante, C. The role of long memory in hedging strategies for Canadian commodity futures. Journal of Agribusiness, 2012. 30, 201-224.

[30] Minot, N. Food price volatility in Africa. Has it really occurred? IFPRI discussion paper 01239, 2012. Washington, USA.https://doi.org/10.2139/ssrn.2197406

[31] Hyun-Joung, J. A long memory conditional variance model for international grain markets.Journal of Rural Development/Nongchon-Gyeongje,2008，31(2), 1-23. Retrieved from http://ideas.repec.org/a/ags/jordng/45654.html

[32] Hurst, H.E. Long-term storage capacity of reservoirs. Transactions of the American Society of Civil Engineers, 1951;116, 770-799

[33] Mandelbrot, B. B. When Can Price be Arbitraged Efficiently? A Limit to the Validity of the Random Walk and Martingale Models, Review of Economics and Statistics, 1971, 53(3), 225-236.

[34] Lo, A. W. Long-term memory in stock market prices, Econometrica, 1991,59, 1279-1313

[35] Geweke, J. and Porter-Hudak, S. The estimation and application of long memory time series models, Journal of Time Series Analysis, $1983,4: 221-238$.

[36] Robinson, P.M.; Henry, M. Long and Short Memory Conditional Heteroskedasticity In Estimating The Memory Parameter of Levels.EconometricTheory, 1999 , doi:10.1017/s0266466699153027

$15(3)$,

[37] Food and Agriculture Organization FAO, 2011.

[38] Roengchai , C, Chia-Lin; Mcaleer, M And Tansuchat,A. Modelling Long Memory Volatility In Agricultural Commodity Futures Returns. Annals of Financial Economics, (2012) 7(2), 1250010-. Doi:10.1142/S2010495212500108

[39] Mohammad Saeid ,R. (2016), Volatility Modelling Using LongMemory-GARCH Models, Applications in S\&P/TSX Composite Index, A Thesis Submitted to TELFER School of Management, University of Ottawa, Ontario in Partial Fulfillment of the Requirements for the Degree of Master of Science in Management

[40] Lee, D. and Schmidt, P. (1996) On the power of the KPSS testof stationarity against fractionally-integrated alternatives, Journal of Econometrics, $73,285 \pm 302$ 